\title{
Acute Deterioration in Pleomorphic Xanthoastrocytoma in a Child
}

\author{
Roka YB ${ }^{1}$, Pandey $\mathrm{SR}^{2}$, Roka $\mathrm{N}^{3}$
}

\begin{abstract}
Pleomorphic Xanthoastrocytoma (PXA) occur in less than $1 \%$ of cases and usually present in the second decade. They present with seizures, focal deficits, intratumoral bleed and rarely with malignant transformation. The few cases that have been reported with acute deterioration in PXA have been secondary to intratumoral bleed. We present a case of PXA in a child that deteriorated secondary to high intracranial pressure which was managed successfully.
\end{abstract}

Key words: Glioma, Intratumural bleed, Pleomorphic xanthoastrocytoma

\section{Introduction}

$\mathrm{P}$ leomorphic xanthoastrocytoma (PXA) is a rare low-grade astrocytoma (WHO II) which occurs in children and young adults ${ }^{1,2,3}$. They present with seizures, focal deficits, intratumoral bleed and rarely with malignant transformation ${ }^{4,5}$. The few cases that have been reported with acute deterioration in glioma have done secondary to intratumoral bleed. We present a case of PXA in a child that deteriorated secondary to high intracranial pressure which was managed successfully.

\section{The Case}

A 13-year male child presented to the emergency with history of altered behavior, reduced vision and severe headache for 1 month. The pain had increased over the last one week and was associated with repeated vomiting. There was no history of fever, trauma or seizure. On examination the child was conscious but sick looking and reluctant to obey commands. His visual acuity was finger counting (FC) both eyes and had bilateral papilloedema. There was no obvious cranial nerve, motor or sensory deficit except for generalized weakness. The $\mathrm{CT}$ showed a multicystic lesion in the tempo-parietal region with severe midline shift and perilesional edema. He was planned for MRI but he suddenly deteriorated with abnormal posturing, bilateral fixed pupils and respiratory distress. Emergency burr hole was done and the superficial cyst aspirated with full neurological recovery in few hours.

The MRI was done next day which showed a large multicystic lesion with an enhancing solid nodule in the inferolateral cyst
'Dr. Yam Bahadur Roka MBBS, MS, MCh, Chief of Neurosurgery, ${ }^{2}$ Dr. Sagar Raj Pandey, MBBS, MD, Chief of Pathology, ${ }^{3}$ Dr. Narayani Roka, MBBS, MS, Ophthalmologist. All from Neuro Cardio and Multispeciality Hospital, Biratnagar-13, Nepal.

Address for correspondence:

Dr. Yam. B. Roka

E-mail: dryamroka@yahoo.com

\section{How to cite}

Roka YB, Pandey SR, Roka N. Acute Deterioration in Pleomorphic Xanthoastrocytoma in a Child. J Nepal Paediatr Soc 2014;34(3):233-235.

doi: http://dx.doi.org/10.3126/jnps.v34i3.10098

This work is licensed under a Creative Commons Attribution 3.0 License.

\section{(c) (i)}

suggestive of PXA (Figure 1). There was gross midline shift and compression of the ipsilateral ventricles with edema.

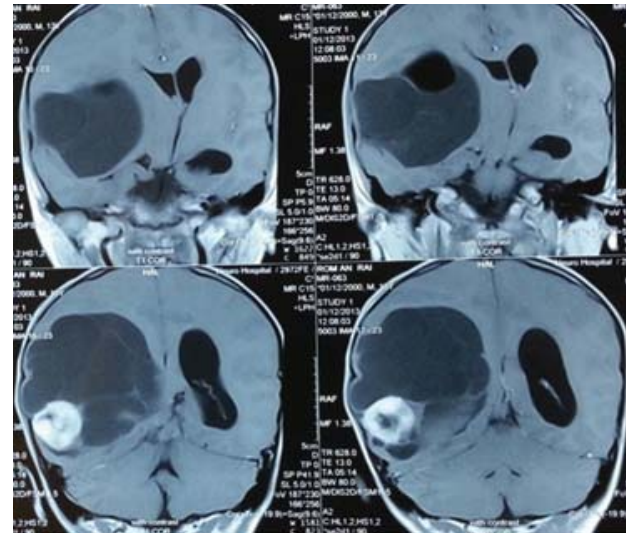

Fig 1: MRI coronal contrast showing a large multicystic tumor with enhancing nodule and gross midline shift. Note the air in the lateral cyst secondary to the previous burr hole aspiration. 
Elective craniotomy was done and microscopic total excision of the tumor was done. Intraoperatively there was a multicystic tumor with an ill-defined firm nodule which was vascular. The cyst was lined with an ill-defined membrane adherent to the surrounding brain. The cysts contained straw colored fluid. The nodule was excised and multiple cysts fenestrated into single cavity (Figure 2).

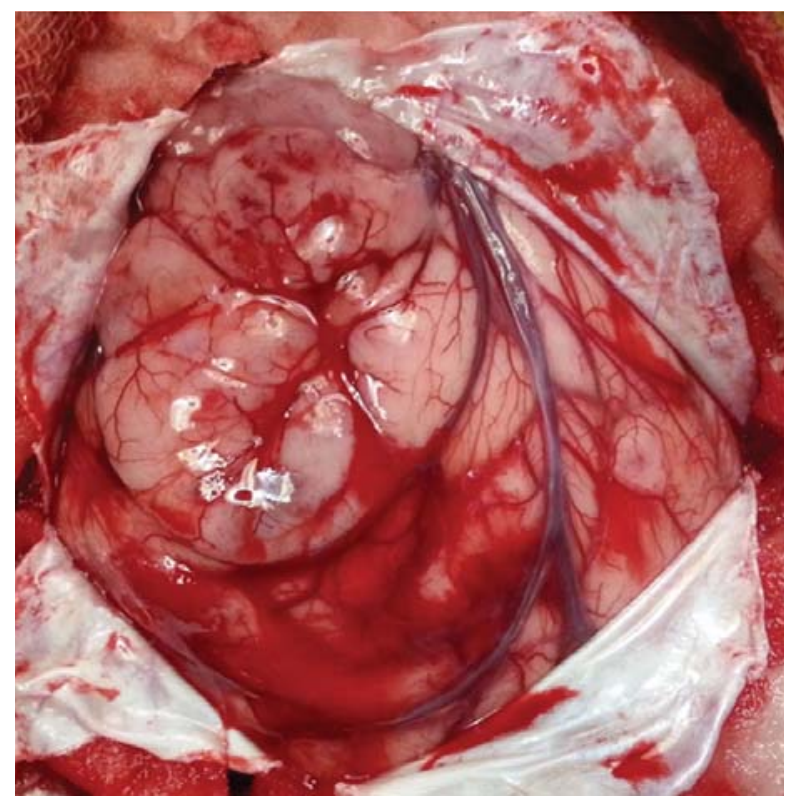

Fig 2: Intraoperative picture showing the tense bluish subcortical cytic lesion. The mural nodule cannot be seen separate from the normal brain parenchyma.

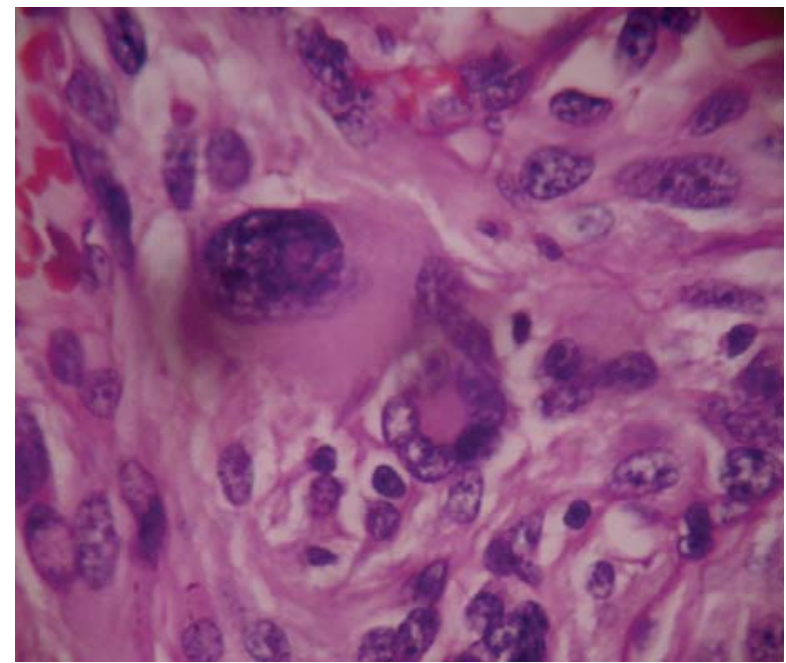

Fig 3: Photomicrograph showing $H$ \&E stain $x 400$ hpf showing atypical cells with prominent nucleoli, hyperchromasia and eosinophilic lipidized cytoplasm. Few tumor giant cells also seen.

The staples were removed on the $8^{\text {th }}$ day and he was discharged on the $10^{\text {th }}$ day. The histopathology was consistent with PXA (Figure 3).
Postoperative contrast CT did not reveal any residual tumor or mass effect. On follow-up at four months he is fine with improved vision and no neurological problems.

\section{Discussion}

PXA occur in less than $1 \%$ of cases and usually present in the second decade. PXA was originally described by Kepes et al. in 1979 and recognized by World Health Organization as a separate disease in $1993^{6}$. The majority are located in the supratentorial compartment although case reports in the cerebellum and spinal cord have been reported. They present with chronic headache, seizure, visual abnormalities or acutely with intratumoral bleed or rapid increase in cyst $^{7}$. The tumors are slow to grow and are low grade histologically (Grade II) with rare malignant transformation. The diagnosis is usually made with help of contrast CT or better with MRI. The latter shows a tumor enhancing nodule with iso to hypo-intense in T1 along with leptomeningeal involvement seen in over $70 \%$ of cases. On T2 it is iso to hyper-intense with minimal surrounding vasogenic oedema. The differentials include ganglioglioma and oligodendroglioma. Pathologically there is cellular pleomorphism comprising of mononucleated/ multinucleated giant cells, spindle cells and granular bodies in a reticulin-rich background with few mitoses; necrosis is usually absent.

The optimal treatment is near total or complete removal surgically if possible ${ }^{9}$. Even if the histologic appearance may be an aggressive tumor, the overall survival is $70 \%-80 \%$ after gross total excision. The role of the use of adjuvant therapy (radiation or chemotherapy) is controversial with no difference in overall survival rate between the 2 groups at 15 years ${ }^{10}$.

These tumors are slow growing and usually present secondary to seizures or visual abnormalities although rapid deterioration has been reported secondary to intratumoral bleed. This case was unusual that there was acute deterioration without any intratumoral bleed suggesting a possible sudden increase in the cyst fluid. Emergency burr hole aspiration relieved the intracranial pressure with full recovery of symptoms. This suggests that simple tapping of the cyst can help to relieve the intracranial pressure and can save lives if neurosurgical facility is not available in the centre or if it takes time to refer the patient. This is in consistent with other cystic lesions of the brain with raised intracranial pressure. 


\section{Conclusion}

PXA are low grade tumors that usually slow growing. The usual presentation is with seizure, headache, visual abnormality and sometimes acute deterioration. Emergency cyst aspiration can help relieve the intracranial pressure and thus save lives in such cystic tumors.

\section{References}

1. Sharma A, Nand Sharma D, Kumar Julka P, KishorRath G. Pleomorphic xanthoastrocytoma - a clinico-pathological review. Neurol Neurochir Pol 2011;45:379-86.

2. Gallo P, Cecchi PC, Locatelli F, Rizzo P, Ghimenton C, Gerosa M, Pinna G. Pleomorphic xanthoastrocytoma: long-term results of surgical treatment and analysis of prognostic factors. $\mathrm{Br} \mathrm{J}$ Neurosurg 2013;27:759-64.

3. $\mathrm{Yu} S$, He L, Zhuang $X$, Luo B. Pleomorphic xanthoastrocytoma: MR imaging findings in 19 patients. Acta Radiol 2011;52:223-28.

4. Wind JJ, Kerr PB, Sweet JA, Deshmukh VR. Pleomorphic xanthoastrocytoma presenting with life-threatening hemorrhage in a child. J Neurosurg Pediatr 2009;3:157-9.
5. Alexiou GA, Moschovi M, Stefanaki K, Prodromou C, Sfakianos G, Prodromou N. Malignant progression of a pleomorphic xanthoastrocytoma in a child. Neuropediatrics 2010;41:69-71.

6. Fouladi $M$, Jenkins J, Burger $P$, Langston J, Merchant T, Heideman R, Thompson S, Sanford A, Kun L, Gajjar A. Pleomorphic xanthoastrocytoma: favorable outcome after complete surgical resection. Neuro Oncol 2001;3:184-92.

7. Lee DK, Cho KT, Im SH, Hong SK. Pleomorphic xanthoastrocytoma with an intracystic hemorrhage : a case report and literature review. J Korean Neurosurg Soc 2007;42:410-12.

8. Marton E, Feletti A, Orvieto E, Longatti P. Malignant progression in pleomorphic xanthoastrocytoma: personal experience and review of the literature. J Neurol Sci 2007; 252:144-53.

9. Im SH, Chung CK, Kim SK, Cho BK, Kim MK, Chi JG. Pleomorphic xanthoastrocytoma: a developmental glioneuronal tumor with prominent glioproliferative changes. J Neuro Oncol 2004;66:17-27.

10. Macaulay RJB, Jay V, Hoffman HJ, and Becker LE Increased mitotic activity as a negative prognostic indicator in pleomorphic xanthoastrocytoma. Case report. J Neurosurg 1993;79:761-68. 